\title{
PROTOTYPIC DEVELOPMENT AND EVALUATION OF A MEDIUM FORMAT METRIC CAMERA
}

\author{
Heidi Hastedt ${ }^{*}$, Robin Rofallski ${ }^{1}$, Thomas Luhmann ${ }^{1}$, Ralph Rosenbauer $^{2}$, David Ochsner $^{2}$, Dirk Rieke-Zapp ${ }^{3}$ \\ ${ }^{1}$ Jade University of Applied Sciences, Oldenburg, Germany; (heidi.hastedt; robin.rofallski; luhmann)@ jade-hs.de \\ ${ }^{2}$ ALPA Capaul \& Weber AG, Zurich, Switzerland; (ralph; david)@alpa.ch \\ ${ }^{3}$ AICON 3D Systems GmbH, Germany; dirk.rieke-zapp@ hexagon.com
}

\author{
Commission II, WG II/7
}

KEY WORDS: photogrammetry, accuracy, metric camera, calibration, length measurement error, large volume metrology

\begin{abstract}
:
Engineering applications require high-precision 3D measurement techniques for object sizes that vary between small volumes $(2-3 \mathrm{~m}$ in each direction) and large volumes (around $20 \mathrm{~m} \times 20 \mathrm{~m} \times 1-10 \mathrm{~m}$ ). The requested precision in object space (1 $\sigma \mathrm{RMS})$ is defined to be within $0.1-0.2 \mathrm{~mm}$ for large volumes and less than $0.01 \mathrm{~mm}$ for small volumes. In particular, focussing large volume applications the availability of a metric camera would have different advantages for several reasons: 1) high-quality optical components and stabilisations allow for a stable interior geometry of the camera itself, 2) a stable geometry leads to a stable interior orientation that enables for an a priori camera calibration, 3) a higher resulting precision can be expected. With this article the development and accuracy evaluation of a new metric camera, the ALPA 12 FPS add|metric will be presented. Its general accuracy potential is tested against calibrated lengths in a small volume test environment based on the German Guideline VDI/VDE 2634.1 (2002). Maximum length measurement errors of less than $0.025 \mathrm{~mm}$ are achieved with different scenarios having been tested. The accuracy potential for large volumes is estimated within a feasibility study on the application of photogrammetric measurements for the deformation estimation on a large wooden shipwreck in the German Maritime Museum. An accuracy of $0.2 \mathrm{~mm}-0.4 \mathrm{~mm}$ is reached for a length of $28 \mathrm{~m}$ (given by a distance from a lasertracker network measurement). All analyses have proven high stabilities of the interior orientation of the camera and indicate the applicability for a priori camera calibration for subsequent 3D measurements.
\end{abstract}

\section{INTRODUCTION}

Several engineering applications require metrology techniques that allow for high-precision 3D measurements for object sizes that vary from large volumes $(20 \mathrm{~m} \times 20 \mathrm{~m} \times 1-10 \mathrm{~m})$ to small volumes (2-3m in each dimension). The resulting precision of a single object point (RMS $1 \sigma$ ) is expected to be within 100-200 $\mu \mathrm{m}$ for large-volume applications and less than $10 \mu \mathrm{m}$ for small volumes. In order to meet the defined high quality requirements, a lasertracking or photogrammetric system can be applied. Various applications are not suitable for using lasertracking due to technical or economic reasons. Introducing a photogrammetric system, several aspects have to be considered: (A) the availability of a suitable optical sensor system that ensures high accuracy over the entire object volume (especially in large volumes) is required, and (B) a suitable scale representation or control network to establish a reliable geometry needs to be provided.

With respect to the sensor system (A), the high relative precision demands of 1:300.000 and higher are to be met. In general, compared to internal measures, the relative accuracy is of up to $100 \%$ lower than its relative precision (Peggs et al., 2009). Potential sources of error can be identified from different investigations on the evaluation of optical systems and configurations for photogrammetric measurements (e.g. Peggs et al., 2009, Luhmann et al., 2015). Primarily influenced by instabilities of the interior orientation components, the accuracy potential might be very limited (Rieke-Zapp et al., 2009). In addition, effects like the variation of distortion within the photographic field have to be considered when aiming for optimum accuracies - especially when applying lenses with high distortion gradients (Brown, 1971, Fraser \& Shortis, 1992). Reznicek et al. (2016) show an increase in mean accuracy when modelling a distant-dependent distortion. Nevertheless, its influence is small for high-quality sensor systems. Peggs et al.
(2009) refer to further factors that influence the bundle accuracy: lack of sensor array flatness (Hastedt et al., 2002), eccentricity of ellipse measurements of photogrammetric targets (Luhmann, 2014a) or optical aberrations (Luhmann et al., 2006).

Therefore, high quality cameras and lenses are required. In particular, imaging sensor and lens have to be connected perfectly and stable with respect to each other during the whole image acquisition process. Algorithmic modelling allows for compensation of most hardware imperfections that are constant for each image, e.g. correction of lens distortion. However, an important prerequisite for standard algorithmic modelling is the minimization of hardware imperfection that will vary for each image. Therefore, the mechanical stabilisation of the cameralens-sensor system in non-metric cameras and the disconnection of flash and camera components is often identified as the key component for accurate results.

The evaluation of different optical systems and configurations with respect to achievable accuracies is an issue for many years. A typical and comparable test scenario is given with the German guideline VDI/VDE 2634.1 (2002). The guideline proposes the length measurement error $(L M E)$ as accuracy quantity, taken as performance-target-deviation from several calibrated lengths in the measurement volume. Rieke-Zapp et al. (2009) summarise the results of an extensive investigation on the evaluation of different systems and configurations. An improvement of the accuracy quantity from $213 \mu \mathrm{m}$ to $52 \mu \mathrm{m}$ for an off-the-shelf camera could be achieved, when mounting the ring-flash to the tripod adapter. Comparative analyses with the Alpa 12 WA (later subsequently modified to the Alpa 12 metric) lead to an accuracy of $124 \mu \mathrm{m}$ for standard processing with a ring flash fixed to the lens, indicating the influence of one source of instability. Applying algorithmic developments that compensate for instabilities of the camera-lens-sensor system or lack of sensor 
quality (Hastedt et al., 2002) improve the accuracy to $29 \mu \mathrm{m}$. Reznicek et al. (2016) validated former results for the Alpa 12 metric achieving a maximum $L M E$ of $40 \mu \mathrm{m}$ without specific algorithmic processing.

Nowadays standard SLR-bodies of best quality (tested out of a batch) are combined with adapted (stabilised) metric lenses to be used as photogrammetric systems. The typical guaranteed precision is specified to $5 \mu \mathrm{m} \pm 5 \mathrm{ppm}(1 \sigma)$ (GSI, 2018). A theoretical length measurement error is then given by $64 \mu \mathrm{m}(3 \sigma)$ for a length of $2 \mathrm{~m}$. The INCA4 from GSI systems is, besides the ALPA 12 WA metric (evaluated in Rieke-Zapp et al., 2009), one of very few metric or metrology cameras. A drawback of this system is the limited usage due to the proprietary software. Nowadays, many photogrammetric systems are tested against the German guideline VDI/VDE 2634.1 to provide users comparable and assessable information on the systems' metric quality, in particular for small volume applications.

In large volume applications, the quality of the sensor system (A) is as important as the introduction of an appropriate scale representation (B). Martin et al. (2016) published results of a comparative test of the INCA3 and an off-the-shelf camera system of lower cost with respect to lasertracker measurements in a volume of $13.5 \mathrm{~m} \times 8 \mathrm{~m} \times 3 \mathrm{~m}$. While the resulting 3D points of the INCA measurement fit within an accuracy of $\pm 86 \mu \mathrm{m}(2 \sigma)$ to the single-station lasertracker points, the usage of an off-theshelf camera lead to deviations of up to $\pm 373 \mu \mathrm{m}(2 \sigma)$. Reznicek et al. (2016) refer to a feasibility study on the datum definition and scale representation in photogrammetric large volume applications. In a test environment of about $20 \mathrm{~m} \times 20 \mathrm{~m} \times 4 \mathrm{~m}$ size, different scale representations are introduced and their influences on the accuracy of the photogrammetric bundle are evaluated. Best results in accuracy are achieved when introducing a control point network of higher order (here given by a lasertracker network measurement). However, the aim was to evaluate the accuracy potential using typical photogrammetric scales or, as a practicable solution, a single distance from a lasertracker measurement, as long photogrammetric scales are not available by now. The length measurement error in large volume results to less than $250 \mu \mathrm{m}$ using the Alpa 12 metric introducing a large scale (representing the diagonal of the measuring volume) or several short scales spread within the measuring volume. However, several short scales lead to high correlations in object space. This scale representation (B) might therefore not be suitable for any application.

The selection of aspects on sensor system quality and scale representation in various object volumes demonstrate the limiting factors in photogrammetric measurements and have to be carefully considered when aiming for high-precision results. They lead to the need of a metric camera for high-precision and large-volume metrology, which already has been an issue for years. Algorithmic developments enable different improvements in the photogrammetric results, but their application is limited in acceptance and verification of the imaging geometry. Metric stability allows for pre-calibration which is necessary for many applications. Therefore, a prototypic development of a metric camera, suitable for nowadays purposes, was conducted leading to a prototypic ALPA $12 \mathrm{fps}$ add|metric (Figure 2). The camera and lens configuration is stabilised by different additional components (see mountings around lens and back in Figure 1 and Figure 2). With this camera a PhaseOne IQ3 series digital back is used. The manufacturing process and requirements are summarised in Rosenbauer et al. (2017). In this contribution, the results of the accuracy evaluation in small and large volume applications will be presented.

\section{METRIC CAMERA - ALPA 12 FPS ADD|METRIC}

A metric camera is defined as a camera with stable opticalmechanical design (Luhmann et al., 2014), leading to a constant three-dimensional position of the perspective centre with respect to the reproducible image coordinate system, and constant distortion parameters, referred to as interior orientation. Any displacement within the camera system and variations in focus or focal length introduced during image acquisition are to be avoided in order to keep a constant interior orientation. The sensor should offer high resolution on a plane pixel architecture and large sensor elements, enabling a high signal to noise ratio. A lens with a static mounting on the camera body and low distortions is another aspect, improving the accuracy of metrology tasks. Table 1 summarises aspects that are of highest interest for the development of a metric camera

\begin{tabular}{|c|c|c|}
\hline & Property & Use \\
\hline \multirow{3}{*}{$\begin{array}{l}\text { Camera-lens- } \\
\text { architecture }\end{array}$} & Fixed focus & \\
\hline & Fixed focal length & Constant interior \\
\hline & Stable housing & \\
\hline & Low lens distortions & Improves image quality \\
\hline \multirow{3}{*}{ Image sensor } & Sensor flatness & Unmodeled parameter \\
\hline & $\begin{array}{l}\text { Large sensor } \\
\text { elements }\end{array}$ & \multirow{2}{*}{ Improves image quality } \\
\hline & High resolution & \\
\hline Flash & flash & $\begin{array}{l}\text { Illumination along optical } \\
\text { axis }\end{array}$ \\
\hline
\end{tabular}

Practical experience results from a preceding non-additive manufactured metric camera, which fulfills all of the requirements mentioned above (Rosenbauer et al., 2017). The ALPA 12 camera platform combines medium format camera backs with high quality lenses to provide optimal image quality for photographic applications. In addition, precise alignment of all parts of the ALPA 12 are present and enable photogrammetric applications.

The ALPA 12 FPS camera body (ALPA, 2018) and lens are taken for further enhancements to build a metric camera. Figure 1 shows different development stages of the metric camera. The development passed several design processes and practical tests. The enhancements are produced using additive manufacturing processes - all development steps and design operations are summarised in Rosenbauer et al. (2017).

The development follows the main aspects:

- Stabilisation of the lens in order to avoid gravity influences by rolling the camera through the optical axis

- Focus fixing and achievement of stable principal distance for the whole measurement process

- Avoid interaction between lens stabilisation and digital back

- Flash mounting separated from the optical components and their enhancements - but along optical axis

- Minimisation of weight

- Minimisation of costs

- Maximisation of flexibility in design and development processes. 

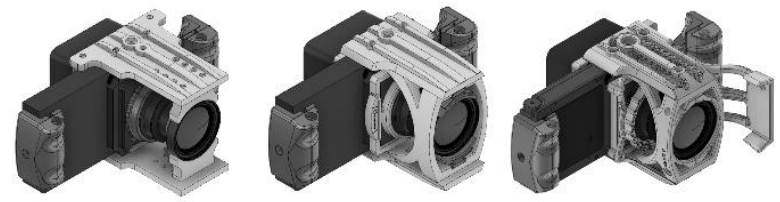

Figure 1. Development stages of the ALPA 12 FPS add|metric

The metric camera ALPA 12 FPS add|metric (ALPA, 2018), shown in Figure 2 and Figure 3 is combined with a HR ALPAGON 4.0/40mm lens and an external flash that is mounted as close to the optical axis as possible. In the first development stages a ring flash was used. This was changed due to further accuracy assessments and the knowledge of high quality image measurements when not using a ring flash - as it complicates the stabilisation and field of view of the metric camera. As sensor system, the following digital backs from PhaseOne are introduced:

- $\quad$ PhaseOne IQ3; 50MP color; 8280 x 3208 Pixel, 5.2 $\mu \mathrm{m}$ pixel size

- PhaseOne IQ3; 100MP color; 11608 x 8708 Pixel; $4.9 \mu \mathrm{m}$ pixel size.

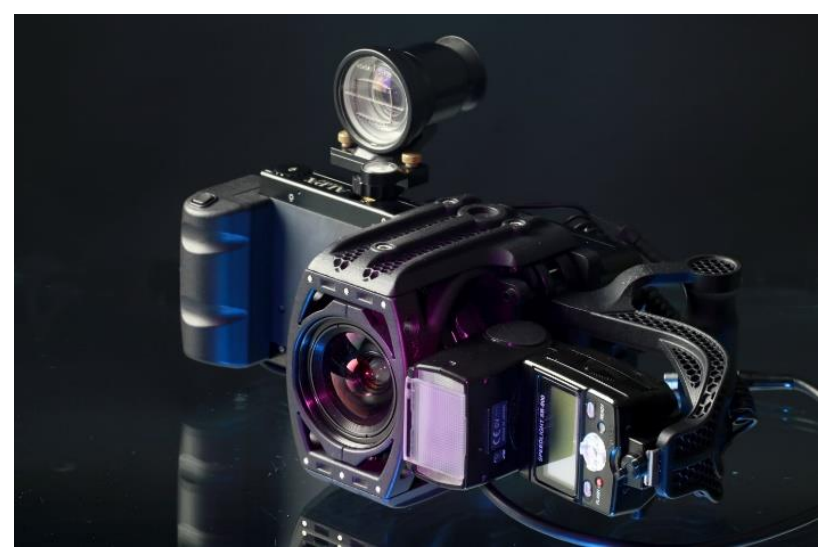

Figure 2. ALPA 12 FPS add|metric front view

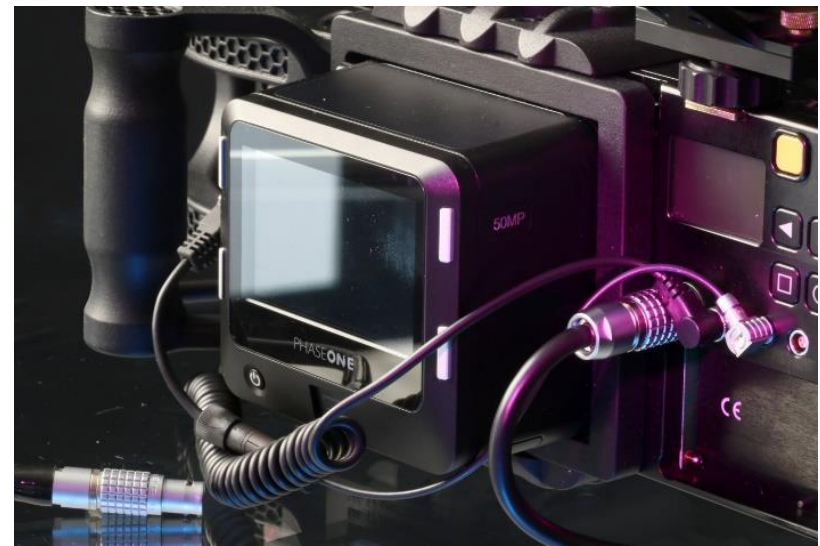

Figure 3. ALPA 12 FPS add|metric detailed view of digital back

\section{ACCURACY EVALUATION IN SMALL VOLUME}

Firstly, the development of the metric camera was evaluated within a standardised accuracy assessment procedure that follows the German guideline VDI/VDE 2634.1 (2002) for optical 3D measuring systems - Imaging systems with point-by-point probing.
The development process was accompanied by two main accuracy evaluation series, where the mountings and flash were modified in between (V1 - first development, ring flash; V2 second development, modified enhancements, external flash) in order to achieve highest accuracies and best handling. With the two evaluation series, several tests of different development steps and configurations are analysed according to VDI/VDE 2634.1 (2002). The main accuracy evaluation of the metric camera is done using the institutes' test scenario (see Figure 4, setup A). In addition, an independent test was investigated at AICON using an equivalent setup (setup B).

\subsection{German Guideline VDI/VDE 2634.1}

The German Guideline VDI/VDE 2634.1 specifies a principle of acceptance test and reverification of optical 3D measuring systems (VDI/VDE 2634.1, 2002). The procedure is based on a cubic test scenario Figure 4, setup A) with a volume of $2 \mathrm{~m} \times 2 \mathrm{~m} \times 1.8 \mathrm{~m}$ and encloses seven measuring lines - calibrated measurement artefacts - arranged in the volume (red lines). The measuring lines consist of at least five test lengths each. The longest test length for each measuring line should at least meet the length of the shortest side of the cubic test volume. The overall longest test length should hold two-thirds of the volume's diagonal. For the test scenario (Figure 4, setup A), seven measuring lines with 58 calibrated artefacts in total are present (see distribution in Figure 4). They are calibrated with an accuracy of less than nine microns, certified by an accredited German laboratory. For photogrammetric bundle adjustment, three additional scale bars are added to the measurements as system scale conditions, arranged along the main coordinate axes.

As accuracy quantity the length measurement error $\Delta l$ is introduced to the analyses as performance-target-deviation with (1)

$$
\Delta l=l_{\text {measured }}-l_{\text {calibrated }}
$$

The maximum, absolute value of the length measurement errors is taken as $L M E_{\max }$.

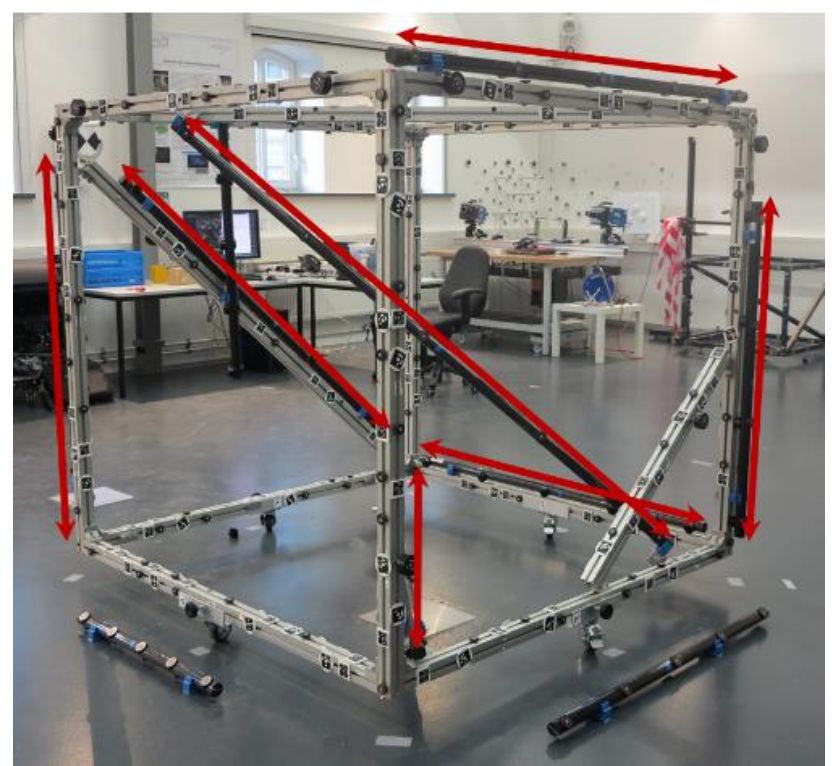

Figure 4. Testfield for accuracy evaluation according to German guideline VDI/VDE 2634.1 (2002) 


\subsection{Acquisition network and measurements}

For each test an image set of 144 images was used for a bundle adjustment. The number of images follows a reproducible arrangement of camera stations around the cubic volume (Figure 5). At 12 positions around the object and in three different height positions, four images each (rolled through the camera axis) are taken. It has to be considered that the resulting intersection angles vary with the visibility of the different object points from the variety of camera stations. Figure 6 shows an example of a resulting acquisition network including exemplary image rays to points from one measuring line (red). The adjacent viewing directions of the camera intersect approximately at $30^{\circ}$ (assuming that some but not all images are taken by pointing the viewing centre to the cubic centre). The angles of intersection from different adjacent height levels in one position are approximately resulting to $13^{\circ}$ and $25^{\circ}$. The mean image scale results to approximately 1:90 with a ground sample distance of $\sim 0.45 \mathrm{~mm}$.

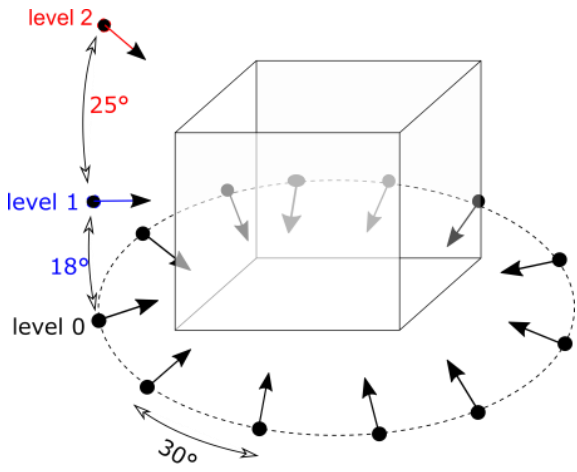

Figure 5. Scheme of image bundle for accuracy evaluation test according to VDI/VDE 2634.1 (2002)

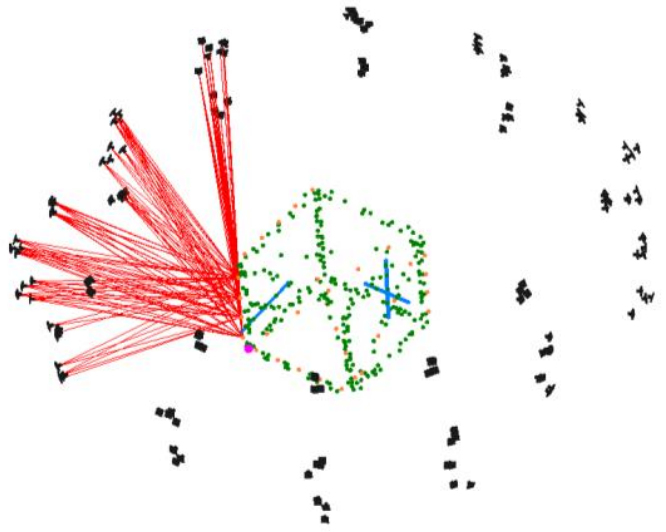

Figure 6. Visualisation of acquisition network (green: object points, orange: points of artefacts, blue: scales; black: camera stations, red: image rays)

The cubic test setup is designed as a permanent construction and located in the institutes' laboratory. The temperature and humidity can be assumed constant, though it neither be measured nor controlled for the accuracy evaluation tests.

The processing is done using AICON 3D Studio software for automatic processing. A free network adjustment is applied, merely three scale constraints are introduced while all object points (measuring lines, tie points) are considered as datum definition. The test volume consists of retro-targets, as well as of standard targets. Both types are taken into account for the evaluation steps. For setup A, the redundancy can be identified to $20.000-24.000$ for bundles using retro-targets and 12.000 to 15.000 for standard targets. This is mainly caused by the amount of targets of the different types. The scenario includes 307 retrotargets and 249 standard targets. Another reason for using two target materials is the fact that, in general, the imaging quality for standard targets decreases with object distances, in contrast to retro-targets, with the acquisition distance. In average, the object points are measured in 33 images (standard targets) and 39 images (retro-targets).

\subsection{Results}

As discussed, different datasets considering influence factors like sensor type, target type, operator and test scenario are analysed. The results are summarised in Table 2 .

\begin{tabular}{|c|c|c|c|c|c|c|c|c|}
\hline \multirow{2}{*}{ 胥 } & \multirow{2}{*}{$\begin{array}{l}\bar{Q} \\
\bar{\Sigma} \\
\overline{0} \\
\bar{d} \\
\bar{d}\end{array}$} & \multirow{2}{*}{ 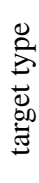 } & \multirow{2}{*}{ 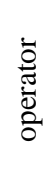 } & \multirow{2}{*}{ 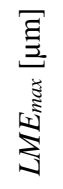 } & \multirow{2}{*}{$\frac{\bar{\Xi}}{\bar{\Xi}}$} & \multicolumn{3}{|c|}{$\sum_{\Omega}^{\infty} \Xi$} \\
\hline & & & & & & $X$ & $\mathrm{Y}$ & Z \\
\hline \multirow{2}{*}{$\begin{array}{l}\mathrm{A}, \\
\mathrm{V} 1\end{array}$} & 50 & $r$ & RR & 20 & 0.19 & 5 & 5 & 4 \\
\hline & 50 & $\mathrm{~S}$ & RR & 24 & 0.26 & 6 & 6 & 5 \\
\hline \multirow{4}{*}{$\begin{array}{l}\text { A, } \\
\text { V2 }\end{array}$} & 100 & $r$ & $\mathrm{HH}$ & 20 & 0.20 & 4 & 4 & 4 \\
\hline & 100 & $r$ & $\mathrm{HH}$ & 20 & 0.22 & 5 & 4 & 4 \\
\hline & 100 & $\mathrm{~s}$ & SN & 23 & 0.29 & 7 & 8 & 6 \\
\hline & 100 & $\mathrm{r}$ & SN & 23 & 0.21 & 5 & 5 & 4 \\
\hline $\begin{array}{l}\text { B, } \\
\text { V2 }\end{array}$ & 50 & $\mathrm{~s}$ & FR & 25 & 0.22 & 8 & 5 & 7 \\
\hline
\end{tabular}

Table 2. Results of accuracy evaluation tests in small volume according to VDI/VDE 2634.1 (2002) for ALPA 12 FPS add|metric (target type: $\mathrm{r}$ - reflective, $\mathrm{s}$ standard)

For all datasets a maximum length measurement error of $25 \mu \mathrm{m}$ could be achieved. The results do not show any dependence from the target type, the operator or the size and resolution of the applied digital back. The single point precision $(1 \sigma)$ is of highest quality for each coordinate direction. For retro-targets, the maximum in any direction results to $5 \mu \mathrm{m}$, for standard targets to $8 \mu \mathrm{m}$ respectively. Thus, a relative precision of $1: 440.000$ is achieved for retro-targets, 1:275.000 for standard targets. Assuming that these qualities are valid for each direction, the standard deviation results to $s_{X Y Z}^{\text {reflective }}=5 \mu \mathrm{m}$ and $s_{X Y Z}^{\text {standard }}=$ $8 \mu \mathrm{m}$. The theoretical length measurement error therefore results with (2, Luhmann et al., 2014)

$$
L M E_{\text {theoretic }}=\sqrt{18} \cdot s_{X Y Z}
$$

to $L M E_{\text {theoretic }}^{\text {reflective }}=21 \mu \mathrm{m}$ and $L M E_{\text {theoretic }}^{\text {standard }}=34 \mu \mathrm{m}$.

Therefore, the resulting $L M E_{\max }$ of less or equal to $25 \mu \mathrm{m}$ meets the expectations. In addition, the standard deviation so refers to high statistical qualities of the bundles.

In order to assess the stability and quality of the interior orientation parameters, an image-variant finite-elements processing (Hastedt et al., 2002) was processed. This approach enables for the modelling of remaining deviations that are not covered by the typical interior orientation model (Brown, 1971, Luhmann et al., 2014). In addition, a varying principle distance and principle point for each image can be applied to the 
adjustment. In particular, if instabilities of the camera system are present, this approach enables an increase in accuracy. Nevertheless, this is not true for the ALPA 12 FPS add|metric. Applying this approach leads to an overconstrained adjustment and does not allow for a qualitative assessment. In order to evaluate the stability of the principal distance and the principal point, exemplarily one of the datasets is divided into four bundles of separated rolling angles. For this test, only images of one rolling direction around the optical axis of two acquisition heights from the described 12 camera stations are taken. Each bundle then includes 24 images. It is assumed, that with this procedure almost equal bundles are available as the determination and size of the parameters are dependent on the arrangement and alignment of the images. The results for the principal distance $\mathrm{c}$ and the principal point $H\left(x_{0}^{\prime}, y_{0}^{\prime}\right)$ are summarised in Table 3 as deviations to the $0^{\circ}$ orientation bundle. These deviations are not significant with respect to the quality of their determination. It leads to the assumption of a high stabilisation level of the lens and the associated parameters.

\begin{tabular}{|c|c|c|c|}
\hline \multirow{2}{*}[\mathrm{mm}]{} & \multicolumn{3}{|c|}{ deviation of $\ldots$ with respect to $0^{\circ}$ orientation } \\
\cline { 2 - 4 } & $90^{\circ}$ left & $90^{\circ}$ right & $180^{\circ}$ \\
\hline $\mathrm{c}$ & -0.0015 & 0.0026 & 0.0015 \\
\hline$x_{0}^{\prime}$ & -0.0008 & -0.0007 & -0.0006 \\
\hline$y_{0}^{\prime}$ & 0.0008 & -0.0023 & 0.0021 \\
\hline
\end{tabular}

Table 3. Deviation of principal distance and principal point of different rolling angles through the optical axis of the ALPA 12 FPS add|metric

\section{ACCURACY EVALUATION IN LARGE VOLUME}

In order to evaluate the quality of the prototypic metric camera (V2) in a large volume arrangement, the system was tested within a feasibility study on the monitoring of the Bremen Cog (Figure 7, Schmik et al., 2018), a medieval wooden shipwreck, at the German Maritime Museum. The object and system arrangement within a ground control network is comparable to large manmade applications as they could exist in manufacturing engineering.

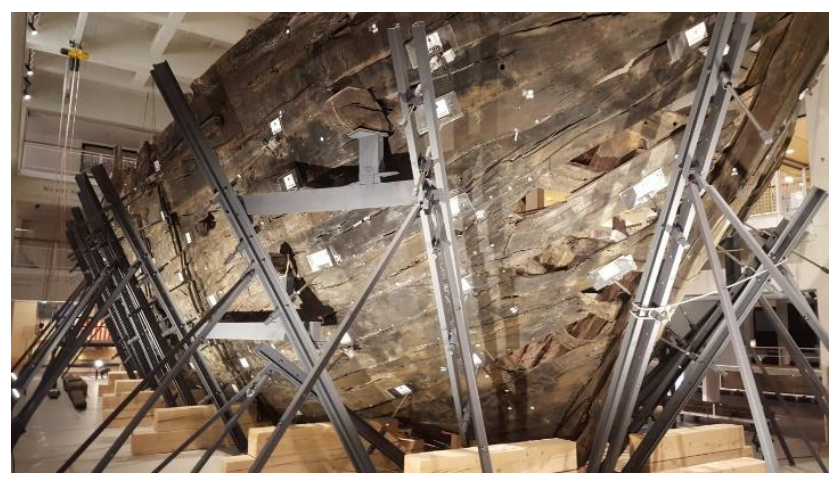

Figure 7. Bremen Cog at the German Maritime Museum

\subsection{Location, environment and ground control network}

The German Maritime Museum is located in Bremerhaven, Northern Germany, at the mouth of the river Weser to the North Sea. The Museum is situated on a small peninsula within the harbour area and directly influenced by the tides. By now, the tidal influence on the museum' building and the Cog is unknown. The exhibition hall stays under permanent temperature control. The influence of the humidity within the museum on the Cog and its subsequent changes within time periods is unknown by now. Influences by sunlight are eliminated by an automatically controlled sun protection system. All targets and calibration artefacts are placed to the environment at least 30 minutes before start of measurements in order to accommodate for environmental influences.

For the evaluation process, a ground control network is established to different exhibition levels in the museum's building structure. Figure 8 shows a laserscan of the exhibition hall with the $\operatorname{Cog}$ in the centre of the building structure. The ground control points are located at all visitors' levels (Figure 8, see numbers in black rectangles). Unfortunately, the ground control network might be influenced by the inhomogeneous tidal changes. The ground control network was measured in July 2017 using a lasertracker. The network quality is estimated to $19 \mu \mathrm{m}$ in $\mathrm{XY}$-direction and $27 \mu \mathrm{m}$ for the Z-direction ( $1 \sigma \mathrm{RMS}$, Schmik et al., 2018). Therefore, the coordinates of the ground control network are of superior precision with respect to the photogrammetric estimation.

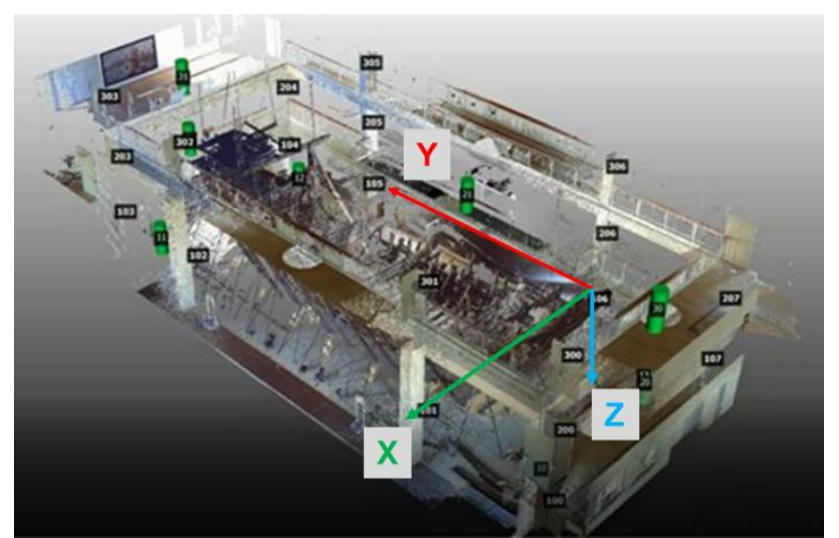

Figure 8. Ground control network and Bremen Cog (Scan visualisation)

In total, $\sim 120$ points are glued to the object as main observation points. In addition, $\sim 450$ coded tie points are placed around the object for automatic processing. 14 ground control points of the lower to exhibition levels are observed by photogrammetry.

\subsection{Acquisition network and measurements}

A first accuracy evaluation using the ALPA 12 FPS add|metric combined with the PhaseOne IQ3 100MP digital back was carried out in July 2017 (I), temporally close to the measurement of the ground control network. A second accuracy assessment using the ALPA 12 FPS add|metric with a PhaseOne IQ3 50MP digital back was performed in December 2017, two datasets were acquired (II-III). The dataset statistics are given in Table 4 . The image scale results to approximately between 1:60 and 1:375 with corresponding approximately ground sample distances of $0.3 \mathrm{~mm}$ to $2.0 \mathrm{~mm}$.

\begin{tabular}{|c|c|c|c|c|}
\hline set & date & images & redundancy & $\begin{array}{c}\text { average rays per } \\
\text { object point }\end{array}$ \\
\hline I & $12-07-17$ & 465 & 27888 & 30 \\
\hline II & $18-12-17$ & 429 & 12389 & 16 \\
\hline III & $19-12-17$ & 436 & 12782 & 17 \\
\hline
\end{tabular}

Table 4. Dataset statistics for accuracy evaluation of the ALPA 12 FPS add/metric in large volume environment 


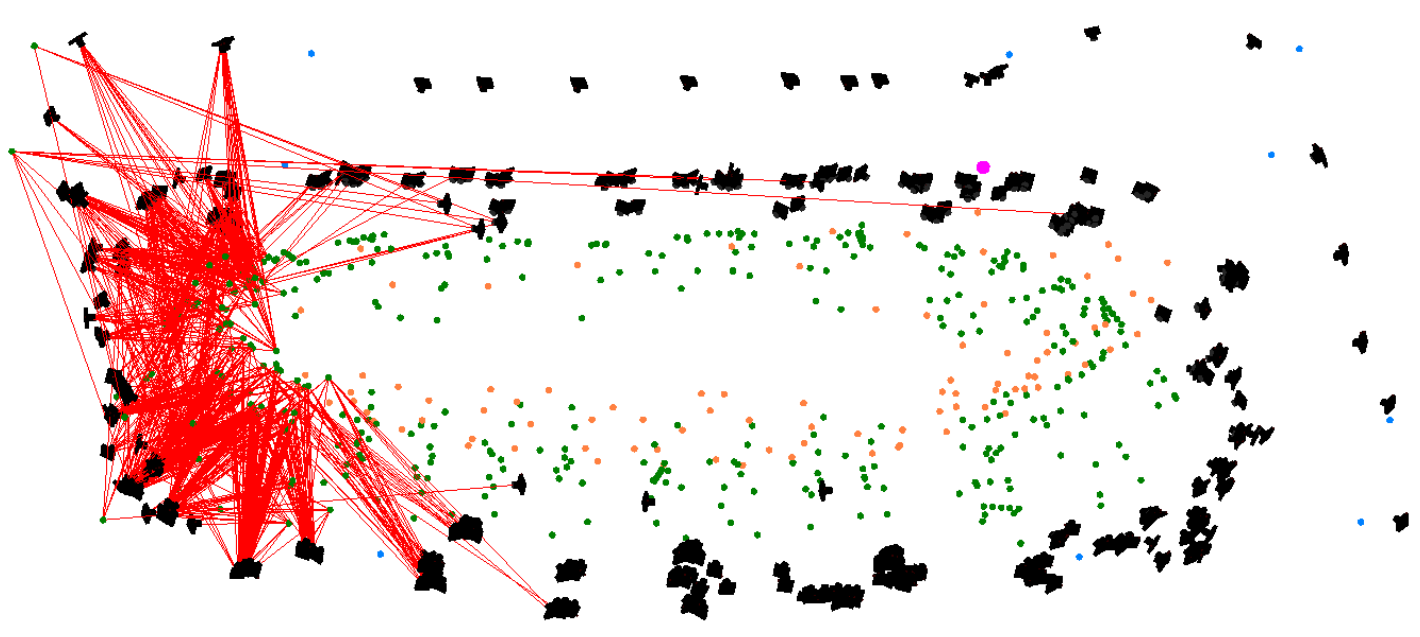

Figure 9. Principal acquisition scheme for large volume environment (green: object points, orange: points on Cog; red: exemplary image rays to object points, blue: control points)

For the accuracy evaluation three datasets were acquired and analysed. For each dataset the acquisition network follows the principal scheme shown in Figure 9. The images are taken in three different height levels around the object. The camera is rolled through the optical axis to allow for a simultaneous camera calibration. The integration of the ground control points to the photogrammetric acquisition is solved through spherical photogrammetric targets that fit to the SMR-adapters. According to the location of the outer ground control points (see blue dots in Figure 10), which are situated outside the typical object volume, best possible images are acquired to allow for appropriate ray intersections. Exemplary image rays are plotted in Figure 9.

\subsection{Results}

The photogrammetric network analysis includes different evaluations of datum definition. The resulting statistics in object point precision $(1 \sigma \mathrm{RMS})$ and relative precision (based on the $28 \mathrm{~m}$ length of the volume diagonal) are summarised in Table 5 . The image measurement quality is comparable within all three sets. The overall precision can be identified being of highest quality. The results from datasets II and III show a slight decrease in precision, compared to the first dataset (I). Nevertheless, a relative precision of 1:280.000 (worst case) for the ALPA metric camera indicates a high accuracy potential. For a comparison, the results of a Nikon D4 with a Zeiss $35 \mathrm{~mm}$ lens, which was tested in parallel, yield a relative precision of 1:157.000. The relative precision remains of same order for small and large volume metrology.

Comparing the acquisition networks of I and II/III, the loss in precision can be identified by the intersection quality of the bundles. The mean object precision for II/III decreases primarily in Y-direction. In addition, the quality of the outer ground control points (see blue dots in Figure 10) is lower than for set I. It is assumed that both effects are primarily caused by the lower resolution of the digital back. For intersection purposes and due to the necessity to include tie points for image processing, the outer ground control points - and other points particularly in Ydirection of largest object extent - remain farthermost and therefore often poor in imaging quality. In addition, the size of the targets was equal and is therefore of less quality for lower resolution. This is also documented by the average number of rays per object point and overall redundancy given in Table 4 . Hence, the precision is of less quality and influences the overall network analysis and statistics. This is obvious when analysing the precision values in Table 5. An overall decrease in precision can be identified when introducing the four outer ground control points for datum definition.

In order to estimate an absolute accuracy quantity, length measurement errors are estimated with respect to distances, calculated from lasertracker measurements (out of the network estimation of the ground control network). The proved lengths are defined between the outer control points ( $28 \mathrm{~m}$ length), the inner control points (18m length) and points close to the Cog (15m length).

The datum definition, the zero-order design problem in nontopographic photogrammetry (Fraser 1984), is of prior relevance for the bundles' precision. Fraser (1984) outlines that the influence factor of the datum definition is highly dependent on the imaging geometry. Thus, the following results have to be considered as accuracy potentials for the metric camera that are based on the specific image sets. Besides this limitation, the choice of the control points used as datum definition is relevant. For the analyses two aspects, a) minimum constraints and b) regular distribution have been considered. Thus, four control points as datum definition or a free adjustment are analysed.

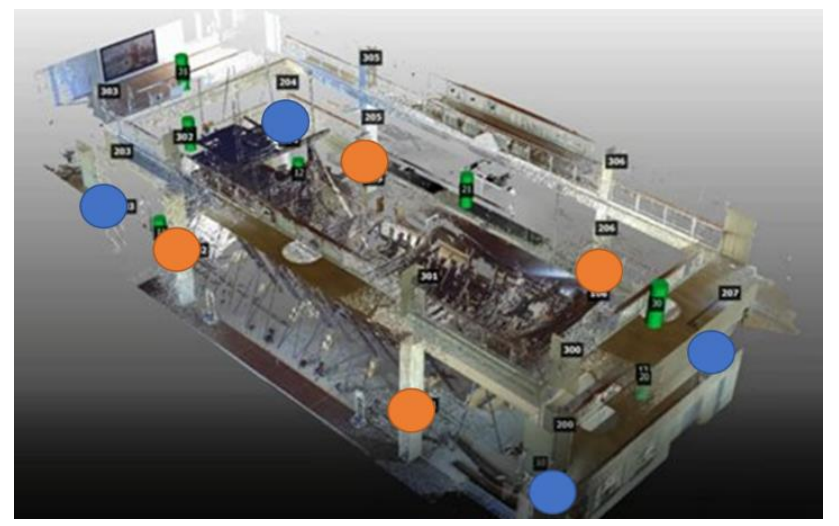

Figure 10. Ground control points for photogrammetric datum definition arranged in large volume environment 


\begin{tabular}{|c|c|c|c|c|c|c|c|c|c|}
\hline \multirow{2}{*}[\mu\mathrm{m}]{} & \multicolumn{2}{|c|}{$\begin{array}{c}\text { datum definition with 4 control } \\
\text { points inside the object volume } \\
\text { (orange dots in Figure 10) }\end{array}$} & \multicolumn{2}{c|}{$\begin{array}{c}\text { datum definition with 4 control } \\
\text { points outside the object volume } \\
\text { (blue dots in Figure 10) }\end{array}$} & \multicolumn{4}{|c|}{ free network adjustment } \\
\hline sensor & $100 \mathrm{MP}$ & \multicolumn{2}{|c|}{$50 \mathrm{MP}$} & $100 \mathrm{MP}$ & \multicolumn{2}{|c|}{$50 \mathrm{MP}$} & $100 \mathrm{MP}$ & \multicolumn{3}{|c|}{$50 \mathrm{MP}$} \\
\hline set & I & II & III & I & II & III & I & II & III \\
\hline RMS & 40.1 & 46.1 & 48.5 & 50.4 & 64.0 & 71.3 & 36.4 & 43.4 & 44 \\
\hline RMS & 29.7 & 51.4 & 43.2 & 35.1 & 63.3 & 53.5 & 33.6 & 60.5 & 55.2 \\
\hline RMS & 21.8 & 29.4 & 31.1 & 28.6 & 39.0 & 45.4 & 14.3 & 22.4 & 23.4 \\
\hline RMS & 54.5 & 75.0 & 72.0 & 67.7 & 98.1 & 100.0 & 51.6 & 77.8 & 74.4 \\
\hline $\begin{array}{c}\text { relative } \\
\text { precision }\end{array}$ & $1: 514.000$ & $1: 373.000$ & $1: 388.000$ & $1: 413.000$ & $1: 285.000$ & $1: 280.000$ & $1: 543.000$ & $1: 360.000$ & $1: 376.000$ \\
\hline
\end{tabular}

Table 5. Results of object point precision $(1 \sigma$ RMS $)$ in large volume application for the ALPA 12 FPS add|metric in microns

\begin{tabular}{|c|c|c|c|c|c|c|c|c|c|}
\hline \multirow{2}{*}[\mathrm{mm}]{} & \multicolumn{2}{|c|}{$\begin{array}{c}\text { datum definition with 4 control } \\
\text { points inside the object volume } \\
\text { (orange dots in Figure 10) }\end{array}$} & \multicolumn{2}{c|}{$\begin{array}{c}\text { datum definition with 4 control } \\
\text { points outside the object volume } \\
\text { (blue dots in Figure 10) }\end{array}$} & \multicolumn{4}{|c|}{ free network adjustment } \\
\hline sensor & $100 \mathrm{MP}$ & \multicolumn{2}{|c|}{$50 \mathrm{MP}$} & $100 \mathrm{MP}$ & \multicolumn{2}{|c|}{$50 \mathrm{MP}$} & $100 \mathrm{MP}$ & \multicolumn{3}{|c|}{$50 \mathrm{MP}$} \\
\hline set & I & II & III & I & II & III & I & II & III \\
\hline $\begin{array}{c}L M E_{\max } \\
28 \mathrm{~m} \text { length }\end{array}$ & 0.19 & $(-) 0.21$ & $(-) 0.42$ & - & - & - & $(-) 0.27$ & $(-) 1.50$ & $(-) 2.27$ \\
\hline $\begin{array}{c}L M E_{\max } \\
18 \mathrm{~m} \text { length }\end{array}$ & - & - & - & $(-) 0.36$ & $(-) 0.45$ & 0.77 & $(-) 0.38$ & $(-) 0.87$ & $(-) 1.11$ \\
\hline $\begin{array}{c}L M E_{\max } \\
15 \mathrm{~m} \text { length }\end{array}$ & 0.17 & 0.34 & 0.39 & $(-) 0.18$ & 0.33 & 0.40 & $(-) 0.13$ & $(-) 0.38$ & $(-) 0.93$ \\
\hline
\end{tabular}

Table 6. Results of maximum length measurement error in large volume application for the ALPA 12 FPS add|metric in mm. Values in italics are of unexpected high magnitude and to be discussed further in the future. Signs for maximum $L M E_{\max }$ are added in brackets for interpretation purposes and trend analysis

The results in absolute accuracy, given by the length measurement errors, are quite promising (Table 6). Set I results in best accuracy, the precision is of best values, too. The absolute accuracy results to a $L M E_{\max }$ of $0.19 \mathrm{~mm}$, the bundle being based on the four inner control points that are well determined. A $L M E_{\max }$ of $0.36 \mathrm{~mm}$ can be reached when introducing four control points outside the object volume. The lower precision of these control points can directly be seen within the lower level of accuracy. For sets II/III the remaining $L M E_{\max }$ are larger. But, as discussed, the low photogrammetric control point precision has to be considered when assessing the accuracy potential.

In order to separate the influence of the object point precision, namely the imaging geometry, from supposed influences from the tidal changes to the ground control network, a free network adjustment was carried out. A particular problem occurs for an appropriate scale representation for large volume applications. Therefore, several short scales are spread within the object volume and introduced as constraints to the photogrammetric bundle adjustment (Reznicek et al., 2016). Hence, the resulting $L M E_{\max }$ of set II and III demonstrate high deviations of up to $2.2 \mathrm{~mm}$ by using the constraint free bundle adjustment (Table 6 , italic values). With all datasets, a negative tendency of $L M E_{\max }$ can be identified. Thus, within the free bundle adjustment all distances remain too short. This is particularly true for set II and III. It has to be discussed, whether the scale representation is not valid for the given imaging bundles, or the ground control network changed due to the tidal influences. Whereas a second network measurement is not carried out by now, the stability of the ground control network is not proven. However, due to good bundle statistics and reliable length measurement errors when introducing the ground control points as datum, a scale problem seems more obvious for the results. Nevertheless, the tidal influences are included to some extent and the poor imaging geometry for sets II/III also lead to lower quality results in absolute accuracy.

The stability and reproducibility of the principal distance and the principal point is analysed with different bundles. For set I the simultaneous calibration of the camera was carried out and taken as basic information. As post-calibration, the camera was taken for measurements on the VDI/VDE 2634.1 (2002) test scenario - using same settings as in set I with just some small modifications for transport. The deviations in principal distance and principal point (Table 7) are underneath their significance values. They refer to a high stability of the main interior orientation parameters. The deviations in distortion are negligible, as they refer to very small distortion values at all. The metric camera is suitable for pre-calibration purposes.

\begin{tabular}{|c|c|c|c|}
\hline & nominal value & $\begin{array}{c}\text { deviation } \\
\text { from VDI1 }\end{array}$ & $\begin{array}{c}\text { deviation } \\
\text { from VDI2 }\end{array}$ \\
\hline $\mathrm{c}[\mathrm{mm}]$ & -42.1532 & 0.0048 & 0.0024 \\
\hline$x_{0}^{\prime}[\mathrm{mm}]$ & -0.4813 & -0.0007 & -0.0007 \\
\hline$y_{0}^{\prime}[\mathrm{mm}]$ & 0.2841 & -0.0002 & -0.0006 \\
\hline
\end{tabular}

Table 7. Values for principal distance and principal point of simultaneous calibration of set I (nominal value) and deviations from the nominal value of VDI calibrations for the ALPA 12 FPS add|metric in mm 


\section{SUMMARY}

The development and accuracy evaluation of the ALPA 12 FPS add $\mid$ metric was presented and discussed. The accuracy assessment was carried out in small and large volume applications. The main development was accompanied with a small volume test scenario based on the German guideline VDI/VDE 2634.1. As accuracy quantity, the maximum absolute value of a set of length measurement errors is chosen. The camera is tested against different sets including influence factors like operator, target type, digital back or test scenario. The derived maximum length measurement error remains below or equal to $25 \mu \mathrm{m}$. The single object point precision yields $5 \mu \mathrm{m}$ for retrotargets and $8 \mu \mathrm{m}$ for standard targets. A relative precision of 1:440.000 for retro-targets and 1:275.000 for standard targets is achieved. The stability of the principal distance and the principal point is demonstrated by dividing one dataset into four single sets, each only including images of same rotation angle through the optical axis. The deviations are very low and show the high stability of the interior orientation parameters.

In addition, the final metric camera was tested within a large volume environment. Within this accuracy assessment different aspects of large volume metrology are analysed. On the one hand, influences of datum definition and scale representation are evaluated. On the other hand, precision and accuracy are determined to prove the accuracy potential of the ALPA 12 FPS add|metric camera. Three sets of imaging bundles are analysed and evaluated. The 3D precision in object space results between $51 \mu \mathrm{m}$ and $100 \mu \mathrm{m}$, depending on the datum definition. The achieved associated relative precision is between 1:543.000 and 1:280.000. In order to allow for an absolute accuracy quantity, length measurement errors are derived from distances in the object volume taken from lasertracker measurements. The maximum absolute value in length measurement error results to $0.2 \mathrm{~mm}-0.7 \mathrm{~mm}$, depending on the datum definition. It has to be considered, that the lower accuracy levels are mainly influenced by a lower imaging geometry due to lower resolution by keeping the target sizes small. The stability of the interior orientation parameters was analysed and proved to be of high quality. The distortion is very low; changes are not provable within the given applications.

The camera ALPA 12 FPS add|metric proves to be a metric camera of high quality and stability for small and large applications as well as for pre-calibration purposes.

\section{REFERENCES}

\section{ALPA, 2018. https://www.alpa.ch/ (29.03.2018)}

Brown, D. C., 1971. Close-Range Camera Calibration. Photogrammetric Engineering, Vol. 37, No. 8, pp. 855-866

Fraser, C.S., 1984. Network Design Considerations for NonTopographic Photogrammetry. Photogrammetric Engineering and Remote Sensing, Volume 50, no. 8, pp. 1115-1126

Fraser, C.S., Shortis, M.R., 1992. Variation of Distortion within the Photographic Field; Photogrammetric Engineering and Remote Sensing, Vol. 58, No. 6, June 1992, pp. 851-855.

GSI, 2018. https://www.geodetic.com/products/systems/v-stars$\mathrm{n} /(29.03 .2018)$
Hastedt, H., Luhmann, T., Tecklenburg, W., 2002. Image-variant interior Orientation and sensor modelling of high-quality digital cameras; In: The International Archives of Photogrammetry, Remote Sensing and Spatial Information Science, Vol. 34(5), pp. 27-32

Luhmann, T., Hastedt, H., Tecklenburg, W., 2006. Modelling of chromatic abberation for high precision photogrammetry. In: The International Archives of Photogrammetry, Remote Sensing and Spatial Information Science, Vol. 36(5), S. 173-178

Luhmann, T., Robson, S., Kyle, S., Boehm, J., 2014. CloseRange Photogrammetry and 3D Imaging. De Gruyter textbook, 2nd edition, ISBN 978-3-11-030269-1

Luhmann, T. (2014a): Eccentricity in Images of Circular and Spherical Targets and its Impact to 3D Calculations. The Photogrammetric Record, Vol. 29, Issue 148, DOI: 10.1111/phor.12084, pp. 417-433.

Luhmann, T., Fraser, C., Maas, H.-G., 2015. Sensor modelling and camera calibration for close-range photogrammetry. ISPRS Journal of Photogrammetry and Remote Sensing, November 2015, doi: 10.1016/j.isprsjprs.2015.10.006

Martin O.C., Muelaner J.E., Dhokia V., Robson S., Kayani A., Maropoulus P.G., 2016: Comparative performance between two photogrammetric systems and a reference laser tracker network for large-volume industrial measurement. The Photogrammetric Record 21 (155), 348-360, doi 10.1111/phor.12154

Peggs, G.N., Maropoulos, P.G., Hughes, E.B., Forbes, A.B., Robson, S., Ziebart, M., Muralikrishnan, B., 2009. Recent developments in large-scale dimensional metrology. Proceedings of the Institution of Mechanical Engineers, Part B: Journal of Engineering Manufacture. DOI: 10.1243/09544054JEM1284

Reznicek, J., Hastedt, H., Ekkel, T., Luhmann, T., Jepping, Ch., 2016. Analysen zur Datumsfestlegung in photogrammetrischen Projekten großer Volumina. Publikationen der DGPF, Band 25, 259-270

Rieke-Zapp, D., Tecklenburg, W., Peipe, J., Hastedt, H., Haig, C., 2009. Evaluation of the geometric stability and the accuracy potential of digital cameras - comparing mechanical stabilisation versus parameterisation. ISPRS Journal of Photogrammetry and Remote Sensing, 64(3): 248-258.

Rosenbauer, R., Fontana, F., Hastedt, H., Luhmann, T., Ochsner, D., Rieke-Zapp, D., Rofallski, R., 2017. Advantages in Additive Manufacturing for a Medium Format Metrology Camera. In: Meboldt M., Klahn C. (eds) Industrializing Additive Manufacturing - Proceedings of Additive Manufacturing in Products and Applications - AMPA2017. AMPA 2017. Springer, Cham; https://doi.org/10.1007/978-3-319-66866-6_28

Schmik, J., Colson, A., Hastedt, H., Luhmann, T., 2018. Photogrammetrisches Monitoring und Deformationsanalyse der Bremer Hanse-Kogge. Photogrammetrie, Laserscanning, Optische 3D-Messtechnik - Beiträge der Oldenburger 3D-Tage 2018. Wichmann Verlag

VDI/VDE 2634.1 (2002): Optical 3-D measuring systems Imaging systems with point-by-point probing. VDI, Düsseldorf 